\title{
COMO OBRA ABERTA: DO CONSTITUIR-SE PROFESSOR NA FORMAÇÃO INICIAL
}

\author{
COMO OBRA ABIERTA: DEL CONSTITUIRSE PROFESOR EN LA \\ FORMACIÓN INICIAL.
}

\section{AS OPEN WORK: TO CONSTITUTE A TEACHER IN INITIAL TRAINING}

\author{
Ana Luiza Bernardo GUIMARÃES ${ }^{1}$
}

\begin{abstract}
RESUMO: A investigação, de abordagem qualitativa, consiste em um estudo de caso, cujo escopo fundamenta-se na análise de como as experiências vivenciadas pelos estudantes em um Curso de Formação Inicial de Professores - Licenciatura em Artes Visuais (LAV), em uma Instituição de Ensino Superior Privada no interior do Estado de São Paulo - são constitutivas da identificação profissional docente. Parte-se da hipótese de que no desenvolvimento da identidade docente, as experiências vivenciadas pelos licenciandos durante o itinerário formativo inicial (a graduação) terminam por criar brechas de ruptura com as crenças e as representações cristalizadas da docência, possibilitando a assunção de outros modos de ser e de estar na profissão. Para a coleta de dados, foram adotados como instrumentos: análise de documentos, questionário e entrevista semiestruturada. E os procedimentos de análise foram alicerçados pelos pressupostos da Análise de Conteúdo (BARDIN, 1977). Os caminhos escolhidos possibilitaram dar a potência que as experiências formativas assumem no processo identitário docente, dando visibilidade à urgência dos cursos de formação inicial de professores em Artes Visuais atentarem para as experiências formativas e simbólicas, criando mecanismos de articulação entre teoria, prática e experiência e de outros modos de ser/estar na profissão e na própria vida.
\end{abstract}

PALAVRAS-CHAVE: Experiência. Identidade docente. Formação de professores em Artes Visuais.

RESUMEN: La investigación, de abordaje cualitativo, consiste en un estudio de caso, cuyo escopo se fundamenta en el análisis de cómo las experiencias vividas por los estudiantes en un Curso de Formación Inicial de Profesores - Licenciatura en Artes Visuales (LAV), en una Institución de Enseñanza Superior Privada - en el interior del Estado de São Paulo - son constitutivas de la identificación profesional docente. Se parte da la hipótesis de que en el desarrollo de la identidad docente, las experiencias vividas por los licenciados durante el itinerario formativo inicial (la graduación) terminan por crear brechas de ruptura con las creencias y las representaciones cristalizadas de la docencia, posibilitando la asunción de otros modos de ser y de estar en la profesión. Para la recolección de datos, fueron adoptados como instrumentos: análisis de documentos, cuestionario y entrevista semiestructurada. Y los procedimientos de análisis fueron fundamentados por los presupuestos del Análisis de

1 Professora Doutora. Faculdades Integradas de Ourinhos. Departamento de Artes Visuais. Email: guimaraesarte@gmail.com / arte@ fio.edu.br 
Contenido (BARDIN, 1977). Los caminos elegidos posibilitaron dar la fuerza que las experiencias formativas asumen en el proceso identitario docente, dando visibilidad a la urgencia de que los cursos de formación inicial de profesores en Artes Visuales atenten para las experiencias formativas y simbólicas, creando mecanismos de articulación entre teoría, práctica y experiencia de otros modos de ser/estar en la profesión y en la propia vida.

PALABRAS-CLAVE: Experiencia. Identidad docente. Formación de profesores en Artes Visuales.

ABSTRACT: The research, qualitative approach, consists of a case study, whose scope is based on the analysis of how the experiences of the students in a Initial Teacher Training Course - Degree in Visual Arts (LAV) in an educational institution Private higher in the state of São Paulo - are constitutive of teaching professional identification. It started from the hypothesis that the development of teacher identity, the experiences of the undergraduate during the initial formation process (graduation) end up creating break holes with beliefs and crystallized representations of teaching, allowing the assumption of other modes being and being in the profession. For data collection, they were adopted as instruments: document analysis, questionnaire and semi-structured interview. And analysis procedures were grounded by the assumptions of Content Analysis (BARDIN, 1977). The paths chosen allowed to give power to the training are assumed experiences in teaching identity process, giving visibility to the urgency of Visual Arts in initial teacher training courses take heed to the formative and symbolic experiences, creating mechanisms of articulation between theory, practice and experience and other ways of being / living in the profession and in life itself.

KEYWORDS: Experience. Teacher identity. Teacher Training in Visual Arts

\title{
Introdução
}

\author{
"Mesmo a obra "acabada", "fechada", é também aberta, na medida \\ que serve a inúmeras interpretações. Cada fruição é uma \\ interpretação e uma execução, pois em cada fruição uma obra revive \\ dentro de uma perspectiva original"
}

ECO, 2008.

Umberto Eco (2008) propõe o conceito de obra aberta para pensar a produção artística como algo inacabado, aberto a várias possibilidades interpretativas e que, por não se fechar em si mesma, apresenta a própria abertura para vida; algo que, no ato de fruição, exigiria do observador uma participação ativa: a liberdade de ressignificação contínua do objeto artístico em um processo marcado pela tensão entre a abertura e a 
definitude. Ante isso, o fruidor passaria a lidar com um conhecimento estético/artístico em construção, não mais inquestionável ou imutável.

Retomar as ideias de Eco (2008) para pensar o processo identitário como obra aberta permite uma compreensão mais ampliada do ser professor, possibilitando ao aluno-mestre $^{2}$ apropriar-se de seus processos formativos em um trabalho de reflexividade crítica sobre as práticas - suas e dos outros - e de (re)construção permanente de uma identidade pessoal e profissional. Neste sentido, não cabe mais pensar a complexidade da profissão docente reduzida ao domínio de conteúdos e sua transmissão. Considerar a identidade docente como obra aberta comporta experimentar arranjos em movimento, repetição, transposição, descontinuidade, virar-se do avesso... E isso exige tempo. Tempo que não é o marcado pelo relógio, o chronos, mas o tempo de aevus, dos eventos, das situações vivenciadas, das narrativas, o tempo da experiência, daquilo que nos passa, nos toca e nos transforma (LARROSA, 2002).

É notório saber que a formação do professor começa antes mesmo de sua formação acadêmica e prossegue durante toda sua vida profissional - especialmente porque a formação para a prática educativa se constitui na tensão entre as determinações estruturais da sociedade, as exigências do sistema de ensino e as perspectivas pessoais do professor (BARREIRO; GEBRAN, 2006). Ademais, são muitos os saberes inerentes à profissão docente, e estes

São construídos ao longo de toda a vida, começando, portanto, antes mesmo da formação inicial, passando por ela e acompanhando toda a formação continuada, eles englobam, inicialmente, teorias e crenças oriundas da vivência particular de cada um, ao longo da vida pessoal e escolar, e que, posteriormente, vão sofrendo influências diversificadas, oriundas dos processos de formação que são consolidados e revalidados na prática docente (MONTALVÃO; MIZUKAMI, 2010, p. 101).

Pensar nesta linha de ação implica compreender o aluno-mestre não como um técnico que deve dominar determinado repertório a ser transmitido ou repassado, nem como vocação, sacerdócio ou destino. Compreende-se a profissão docente como um produto de si, um sujeito que se produz em sua prática de ensinar e de aprender (PEREIRA, 2013). Nessa ação de esquadrinhar-se constantemente, os alunos-mestres, começam a questionar sobre como têm ensinado e sido ensinados, buscando uma

\footnotetext{
${ }^{2}$ Aluno-mestre: termo utilizado para identificar os sujeitos que vivenciam a dupla condição, de alunos na
} Licenciatura em Artes Visuais e de professores no ensino formal (ZABALZA, 1994). 
relação maior entre aquilo que pensam, apreendem e realizam, precisando da vida e do viver para que o ensino e a aprendizagem de Arte se efetivem.

Assim, a pesquisa que ora se pronuncia, se baliza por ser um espaço/tempo de reflexão, em uma prática pedagógica concreta com os licenciandos em Artes Visuais, na ânsia de compreender de que forma as experiências vivenciadas na graduação atuam na constituição identitária de sua profissão.

\section{Os processos identitários e a formação inicial na licenciatura}

A formação inicial dos professores implica tanto a valorização da própria formação quanto o redimensionamento dos saberes profissionais vivenciados na prática - compreendidos como "[...] os saberes, saberes-fazer, competências e habilidades que servem de base ao trabalho dos professores" (TARDIF, 2012, p. 112). Em razão disso, é preciso coerência entre os processos de aprender a ensinar e a constituir-se professor, levando em consideração a constante reflexão epistemológica da prática, de modo que “[...] aprender a ensinar seja realizado através de um processo em que o conhecimento prático e o conhecimento teórico possam integrar-se num currículo orientado para a ação" (GARCIA, 1999, p. 29).

Neste pensar, o eixo balizador dos currículos de formação inicial deve ser o desenvolvimento da capacidade reflexiva, a competência de refletir sobre a prática docente, com o objetivo primeiro de interpretá-la, estabelecendo os elos necessários à compreensão da realidade social e da docência. Isto posto, devemos também considerar a questão da identidade docente como um dos eixos norteadores das discussões e reflexões na formação inicial. À guisa de um conceito, podemos ponderar que a identidade docente é a forma como os professores definem a si mesmos e aos outros,

É uma construção do "si mesmo" profissional que evolui ao longo da carreira docente e que pode achar-se influenciado pela escola, pelas reformas e pelos contextos políticos, que inclui o compromisso pessoal, a disposição para aprender a ensinar, as crenças, os valores, o conhecimento sobre a matéria que ensinam, assim como sobre o ensino, as experiências passadas, assim como a vulnerabilidade profissional (GARCIA, 2009, p. 112).

Essa concepção de identidade é compreendida como o conjunto de características próprias e exclusivas de uma pessoa, marcada pelas experiências vivenciadas no campo pessoal e profissional, e que, entranhadas umas nas outras, 
delimitam o espaço de ser do docente - uma identidade que é construída no calor das interações, mas que se configura no 'seu' espaço particular de humanidade.

A identidade não é um dado adquirido, não é um produto. A identidade é um lugar de lutas e de conflitos, um espaço de construção de maneiras de ser e de estar na profissão. A construção de identidades passa sempre por um processo complexo, graças ao qual cada um se apropria do sentido de sua história pessoal e profissional, “[...] é um processo que necessita de tempo: um tempo para refazer identidades, para acomodar renovações, para assimilar mudanças" (NÓVOA, 1995, p. 6).

Compreendemos o processo identitário docente como uma realidade em movimento, como espaço/tempo de ser/fazer, que é desenvolvido ao largo da vida e em diálogo com infinitas variáveis; um processo que não se principia ou se esgota durante a formação inicial, mas que se consolida nesta e que se prolonga durante toda a sua existência profissional; como este percurso de ser e de estar no mundo, como uma rede em que todas as relações - externas e internas - são tecidas pelo sujeito no próprio processo formativo, que não se concebe como uma substância pronta e acabada, mas como permanente processo de transformação de si e que, por isso mesmo,

Não se constrói por acumulação (de cursos, de conhecimentos ou de técnicas), mas sim através de um trabalho de reflexividade crítica sobre as práticas e de (re)construção permanente de uma identidade pessoal. Por isso é tão importante investir a pessoa e dar estatuto ao saber da experiência (NÓVOA, 1995, p. 25).

Deste modo, o processo identitário não é um atributo fixo para uma pessoa, mas sim uma espécie de continuum, um fenômeno que agrega múltiplas relações e que acontece também no terreno da subjetividade; um movimento de vir a ser construído com base nas relações que se estabelecem tanto com o repertório que os licenciandos têm acerca da docência, quanto com as relações sociais que se efetivam nos cursos de formação inicial, em especial quando os estudantes têm maior contato com a prática docente, no estágio e na iniciante atuação profissional.

Como forma de ampliar as discussões efetuadas, podemos trazer as contribuições de Garcia (2009), para quem a constituição das identidades é permeada por elementos que sempre a caracterizaram diante da identidade de outras profissões, e que devem, justamente por isso, servir de desafio à transformação da nossa própria profissão. 
Entre esses elementos, podemos destacar o fenômeno conhecido como 'socialização prévia' (GARCIA, 2009), uma vez que a “[...] docência é a única das profissões em que os futuros profissionais se veem expostos a um maior período de observação não dirigida em relação às funções e tarefas que desempenharão no futuro" o que leva os professores a "[...] desenvolverem padrões mentais, crenças sobre o ensino, a partir do período tão prolongado de observação como alunos" (GARCIA, 2009, p. 116).

Nestes 'milhares de horas' na qualidade de alunos, os futuros docentes vão recebendo, mesmo sem perceber, modelos docentes com os quais se identificam, até mesmo porque "[...] começamos a aprender a ser professor com o professor que temos, aprendemos a ser ou não ser, o que queremos e o que não queremos" (PIMENTA, 1999, p. 13). Tal período deve ser visto com extrema atenção, pois é nele que se assumem e veiculam determinados estereótipos, esquemas e imagens da docência que são difíceis de eliminar ou superar.

Em um curso de formação inicial, os estudantes que iniciam a licenciatura trazem no seu imaginário tanto as experiências e as relações que tiveram com os seus professores da Educação Básica, os modelos docentes vivenciados, quanto as imagens propaladas pela mídia a respeito da profissão, como também os discursos proferidos pelos familiares e amigos em torno da escolha profissional; configurando, assim, uma vertente na construção da sua identidade docente. E reelaborar esses processos formativos de constituição de si pode ser um bom começo!

Os alunos ingressantes na licenciatura não são uma 'tábula rasa', já possuem ideias e crenças estabelecidas sobre o ensino e a aprendizagem, já trazem consigo 'modelos de ser' professor, que incluem: (a) aspectos pessoais, determinantes de sua visão de mundo, em torno de si mesmo e dos demais, além das relações escolasociedade; (b) as crenças a respeito da matéria que se ensina, bem como a forma de fazê-lo; (c) sua experiência como estudante, que contribui para formar juízos acerca do que é ensinar e qual é o papel do professor - crenças tais que terminam tanto por atuar como lentes de sentido aos conhecimentos e às experiências com que se deparam, como barreiras à mudança, limitando outras concepções sobre o ensino e sobre a aprendizagem.

Uma das alternativas diante da opacidade dessas crenças, consiste na promoção de espaços e tempos de reflexão e de reconsideração de suas concepções epistemológicas, promovendo uma tomada de consciência do que eu sou para aquilo 
que quero vir a ser. Isso significa que as Instituições de Ensino Superior (IES) e os formadores de professores precisam voltar os olhos para os cursos de formação inicial como um fator decisivo na promoção do conhecimento profissional, e de todos os aspectos que envolvem a profissão docente, comprometendo-se com a mudança e a inovação do contexto em que se inserem.

Para Garcia (2009), uma das chaves da constituição desse processo identitário docente é proporcionada pelo conteúdo que se ensina, pois "[...] a matéria que ensinamos ou pretendemos ensinar não fica à margem de nossas concepções. A forma como conhecemos uma determinada disciplina ou área curricular afeta a forma como a ensinamos" (GARCIA, 2009, p. 118). Isto é, o conhecimento que os alunos-mestres possuem do conteúdo a ensinar também influi no que e no como ensinam.

O conhecimento profundo daquilo que se ensina, o conteúdo e suas formas de abordagem incluem diferentes componentes, em especial o conhecimento sintático (compreendido pelo conhecimento dos paradigmas de investigação em cada disciplina) e o conhecimento substantivo (conhecimentos gerais da matéria que leciona, seus conteúdos, conceitos específicos, definições). O pouco conhecimento acerca do conteúdo termina por trazer consequências lamentáveis, tanto no que se refere a preparação das aulas dos alunos-mestres - vista muitas vezes como recordação de informação e cópia - quanto na efetivação delas, pois o conhecimento superficial limita a compreensão dos conceitos e leva-os à representações equivocadas da disciplina.

Em face de uma formação inicial cada vez mais compartimentalizada, fragmentada e pobremente organizada, urge a recomposição dos currículos dos cursos de formação inicial com vistas à construção das identidades docentes, pois “[...] não se trata somente de ensinar aos futuros docentes estratégias para serem professores, mas se trata de que vivam essas estratégias mediante a criação de situações de vivência, convivência e colaboração" (HERNÁNDEZ, 2005, p. 32).

O processo de formação inicial precisa oportunizar aos estudantes conhecimentos, habilidades e atitudes que fortaleçam o seu desenvolvimento enquanto profissionais reflexivos e investigadores de sua própria atuação, e nesse direcionamento, o movimento de formação deve ser o desenvolvimento da capacidade reflexiva, baseada na análise sua própria prática, afinal "torna-se o que se é” sendo no mundo (LARROSA, 2011). O nó está justamente na necessidade de promover esse encontro entre teoria, prática e reflexão! 
Faz-se necessária uma atitude investigativa e reflexiva que considere a teoria e a prática, uma atitude que não tema a utopia e que, por isso mesmo, valha-se da observação, do debate, do contraste de pontos de vista, da análise da realidade social, da reflexão... da aprendizagem que não se escora na insuficiência do cumprimento das horas de estágio, mas que agita-se nos estudos de caso, nas dramatizações, nas simulações, na reflexão das experiências e nas tematizações da prática; uma aprendizagem de ser professor construída na dinamização dos dispositivos investigativos e reflexivos, que confronte seus fundamentos teóricos e articule prática e reflex

ão.

\section{Da reflexão na constituição si: percursos de ser/estar na formação inicial dos licenciandos}

"Uma das bonitezas de nossa maneira de estar no mundo e com o mundo, como seres históricos, é a capacidade de, intervindo no mundo, conhecer o mundo. FREIRE, 1996

Essa boniteza de que nos fala Freire (1996) reside na nossa capacidade de refletir sobre o mundo e a partir desta, transformar o que nos habita e o onde nós habitamos. Tal reflexão não se pauta pelo pensar corriqueiro, desprovido de intencionalidade, mas reside na capacidade de fazer escolhas, de emitir juízos e de estabelecer relações de qualidade, que configuram o cerne do professor reflexivo e inquietador de pensares e agires sobre sua prática, professor que não se deixa conformar pela práxis imitativa, pois sabe que esta se configura

Pelo estreitamento do terreno da imprevisibilidade, tornando imutáveis tanto as finalidades quanto os modos de agir, vez que, independentemente das necessidades, limitações e possibilidades apresentadas pelos sujeitos e contextos, já se define, de antemão, o que fazer e como fazer, perdendo-se, assim, a incerteza e a aventura do processo criador, reduzindo o fazer à repetição, à mera imitação de ações criadas por outrem (MATTAR, 2011, p. 171).

Ao contrário, o estudante da Licenciatura, que investiga sua própria prática e seus processos de aprendizagem, concebe-a como artística, sabe que ela não está no manual, presa a uma fórmula. Antes, passa por estados de invenção e de experimentação produzidos por cada situação. Lidar com essa capacidade de improvisar e de fazer 
escolhas necessita de um perfil docente reflexivo, isto é, um aluno-mestre questionador que, baseando-se na vontade, na intuição, na pesquisa, na experimentação e na reflexão busca soluções para os problemas.

A corrente do professor reflexivo, enquanto abordagem teórico-metodológica na formação de professores, emergiu no início dos anos 1990, fundamentada na retomada dos estudos deweyanos e na quebra com o modelo da racionalidade técnica - modelo “3+1” na formação inicial. A ação reflexiva proposta por Dewey (1952), na formação inicial de professores, apresentava-se como uma possibilidade de ruptura com os modelos formativos existentes e assunção de um novo tempo: o de incluir como referência a investigação reflexiva da e na prática pedagógica, uma vez que esta implica uma

Uma consideração ativa, persistente e cuidadosa daquilo em que se acredita ou que se pratica, à luz dos motivos que o justificam e das consequências a que conduz. Não é, portanto, nenhum conjunto de técnicas que possa ser empacotado e ensinado aos professores (DEWEY, 1952 apud ZEICHNER, 1993, p. 18)

Neste sentido, quando pensamos na prática reflexiva na formação inicial de professores, estamos destacando a própria ação reflexiva enquanto desenvolvimento do pensamento e da ação do ser professor, enquanto característica fundamental para a constituição de sua identidade docente. A reflexão implica, também, o mergulho consciente do aluno-mestre no universo de suas experiências, um cenário carregado de valores simbólicos, de conotações e correspondências afetivas, questões políticas e interesses sociais. Não há neutralidade reflexiva, uma vez que a todo momento nossas concepções e crenças se confrontam com a análise que realizamos do ato educativo e, por que não dizer, da nossa própria formação, como também advoga Paulo Freire (1998, p. 105), ao afirmar que "[...] é desvelando o que fazemos desta ou daquela forma, à luz de conhecimento (...) que nos corrigimos e nos aperfeiçoamos. É a isso que chamo pensar a prática e é pensando a prática que aprendo a pensar e a praticar melhor" (grifos nossos).

Esse pensamento reflexivo, esse estado permanente de dúvida e de análise - e também de autoconhecimento - possibilita a ação de uma finalidade consciente, libertando o homem de um pensamento rotineiro e, por isso mesmo, previsível. A problematização da prática e das experiências vividas motiva a ação reflexiva e o pensamento, de forma a torná-los fonte de conhecimento. Desta forma, para o 
desenvolvimento da prática reflexiva na formação inicial de professores, é preciso aclarar a necessidade de solução de determinado problema, determinado acontecimento, que pode vir à tona por meio da experiência, e que engloba

Todos os tipos de observação e práticas de ensino num programa de formação inicial de professores: experiências de terreno que precedem ao estágio, experiências de ligação à prática no âmbito das disciplinas ou módulos específicos e experiências educacionais dos alunosmestres no âmbito do "ensino normal" (ZEICHNER, 1993, p. 53).

O pensamento reflexivo oferece ao futuro professor a capacidade de planejar, de projetar tendo em vista uma realidade próxima. Projetar assume o sentido de escolha e de busca consciente, de uma postura de quem quer aprender mais - e por isso se propõe a transformar as verdades tidas como absolutas e as mentiras tidas como incertas -, de quem procura investigar a curiosidade do mundo baseado em um investimento pessoal, “[...] um trabalho livre e criativo sobre os percursos e os projetos próprios, com vista à construção de uma identidade, que é também uma identidade profissional" (NÓVOA, 1995, p. 25).

A reflexão envolve o projetar. O projetar inclui romper e transformar. Refletir, portanto,

Envolve o movimento dinâmico, dialético, entre o fazer e o pensar sobre o fazer. [...] O que se precisa é possibilitar, que, voltando-se sobre si mesma, através da reflexão sobre a prática, a curiosidade ingênua, percebendo-se como tal, se vá tornando crítica. [...] A prática docente crítica, implicante do pensar certo, envolve o movimento dinâmico, dialético, entre o fazer e o pensar sobre o fazer (FREIRE, 1996 p. 38).

Pensar reflexivamente alavanca a invenção e o planejamento. Por meio da reflexão constante, o aluno-mestre aperfeiçoa e antecipa as consequências resultantes de suas ações - seja para evitá-las ou para respaldá-las -, sem bússolas a indicar caminhos, pois o "[...] o importante é que a reflexão seja um instrumento dinamizador entre teoria e prática" (FREIRE, 1996, p. 39), possibilitando a ação transformadora.

Zeichner (1993, p. 21) assevera que “[...] há uma separação entre teoria e prática que tem de ser ultrapassada: as teorias existem exclusivamente nas universidades e a prática existe apenas nas escolas”. Esse descompasso não potencializa a ação reflexiva, haja vista que ambas coexistem, porém de formas estanques; enquanto a universidade for o centro da cultura acadêmica, e a escola, seu laboratório de comprovação teórica, a formação inicial dos licenciandos será infundada e superficial. Ninguém vive apenas de 
teoria, nem tão somente de prática; é necessidade premente que ambas se conectem e que a formação inicial seja lócus de um processo reflexivo primeiro. Processo este que

\begin{abstract}
Não consiste em uma série de passos ou procedimentos para serem usados por professores. Mais do que isso, ela é uma forma integrada de perceber e responder a problemas, uma forma de ser professor. Ação refletiva envolve, também, mais do que solução-de-problemas por procedimento lógico e racional. Reflexão envolve intuição, emoção e paixão, e não é algo que pode ser acondicionado em pacotes, como um programa de técnicas para professores usarem. (ZEICHNER; LISTON, 1996, p. 9).
\end{abstract}

Se a reflexão não é mera operação mental, por que é que ainda a reduzimos a um leque de fórmulas burocráticas? Como já dissera o autor, a reflexão, vista como um processo de conhecimento e de autoconhecimento, envolve a paixão, a emoção, a intuição e também a racionalidade para uma emancipação das práticas. E acreditamos que seja esse aspecto um dos elementos basais da formação inicial: a dos alunos-mestres e a dos próprios formadores estudarem a maneira como ensinam, a fim de melhorá-la com o tempo, partindo e partilhando suas próprias experiências e responsabilizando-se pelo seu próprio desenvolvimento docente.

Pensar reflexivamente dá significação às coisas. Enriquecer essas coisas com um sentido significa, também, uma vivência efetiva da palavra que se professa no exercício cotidiano do ambiente escolar (MACHADO, 2000). Sem esse afinado compasso, correse o risco de tornar inócuo o cultivo dos valores fundamentais à construção e consolidação do arquétipo humano. Nada pode ser mais insalubre na formação do jovem professor do que conviver com o discurso elaborado por valores e a prática opressiva nos procedimentos escolares. "Faça o que eu digo, mas não faça o que eu faço" não pode ser uma máxima a se efetivar nos bancos escolares e nas ações docentes. Nada parece menos íntegro que perceber-se marionete de um discurso que ora beneficia uns, ora outros, porque não se solidifica nas ações cotidianas.

A reflexão, sobre este ponto de vista, não é assumida como uma prática que garanta a conservação do passado ou a fabricação do futuro, mas como uma experiência formativa, um movimento que produz intervalos, diferenças, rupturas, aberturas para encontros em porvir. Quando se defende a ideia de que o professor deve ser um profissional reflexivo, não se está revelando nenhum conteúdo para a reflexão ou propondo qual deve ser o campo de reflexão e seus limites. Entende-se que o potencial de reflexão é algo próprio de cada um, e não há modelo a ser seguido. Ser questionador 
e reflexivo, ter capacidade para julgar e tomar decisões se configura como uma possibilidade de conquista de autonomia diante da racionalidade técnica e da massificação da prática a que estamos sujeitos cotidianamente.

Neste contexto, assume-se a bandeira de que as experiências formativas, sejam elas de ordem didáticas e/ou estéticas, vivenciadas no decorrer da graduação, possuem valor inigualável para a formação do 'ser professor', pois ao se constituírem na mediação entre conhecimento e vida, as experiências terminam por gerar um saber da existência - e esse modo de pensar a existência não se aparta do modo de refletir a sua existência enquanto professor. Para Larrosa (2002, p. 27), esse saber da experiência

Tem a ver com a elaboração do sentido ou do sem sentido do que nos acontece, trata-se de um saber finito, ligado a existência de um indivíduo ou de uma comunidade humana particular. Ou, de um modo ainda mais explícito, trata-se de um saber que revela ao homem concreto e singular, entendido individual ou coletivamente, o sentido ou o sem sentido de sua própria existência, de sua própria finitude. Por isso, o saber da experiência é um saber partícula, subjetivo, contingente, pessoal. [...] A primeira nota sobre o saber da experiência sublinha, então, sua qualidade existencial, isto é, sua relação com a existência, coma vida singular e concreta de um existente singular e concreto. A experiência e o saber que dela deriva são o que nos permite apropriar-nos de nossa própria vida.

Trazer à tona os saberes da experiência dos licenciandos em Artes Visuais implica, também, aclarar o conceito de experiência (DEWEY, 1959a) e de experiência como acontecimento (LARROSA, 2011). Embora de tempos educacionais e contextos sócio-históricos distintos, o diálogo entre as ideias dos dois pensadores se harmoniza pelo potencial 'formador' que a experiência, na qualidade de constituidora do sujeito, possui. Para ambos, viver uma experiência não se limita a 'saber fazer' algo, mas a viver determinadas condições que possibilitem que a experiência se efetive e transforme o próprio sujeito: para um, a relação entre o sujeito e sua subjetividade e, para outro, no contato entre o sujeito e o mundo exterior.

Com Dewey (1959a), o exercício inicial de compreensão do conceito de experiência se pauta tanto pela crítica a educação tradicional quanto pelo foco no protagonismo do estudante. Ele concebe a experiência como uma unidade complexa, atravessada pelo fluxo e pelo refluxo dos pensares e da significação que o sujeito confere àquilo que vivencia, na interação com o mundo exterior. A experiência, para ele, envolve a consciência de uma continuidade, um movimento que desencadeia outros processos, outros pensares e, até mesmo, outras experiências, porque a qualidade da 
experiência advém da reflexão, que une tanto o 'já sabido' quanto aquilo que se espera aprender, o elemento 'novo'. Neste sentido, a atividade reflexiva baseada na experiência é o que garante a aprendizagem, a mudança e a continuidade de um pensar acerca de suas possibilidades e consequências, um pensar que auxilia na compreensão da experiência e em sua explicitação (DEWEY, 1959b).

Ter uma experiência e proporcionar uma experiência perpassam pela escolha, pela reflexão e, ao mesmo tempo, pela capacidade de interrupção da massificação da prática e da negação da 'síndrome de Gabriela'³ Com Dewey (1959a, 1959b, 2011), temos a proposta de formar um professor reflexivo que combine as capacidades investigativas com as atitudes de abertura mental, responsabilidade e honestidade, um ser humano mais crítico e reflexivo diante da realidade em que atua. Nessa concepção, vida, experiência, reflexão, aprendizagem e formação profissional são conceitos interconectados - o que dialoga com as concepções de Larrosa (2002) sobre a experiência, que pressupõe um acontecimento, algo que produza efeitos no que se é, no que se pensa, no que se sabe e no que se sente. Desta forma,

Não há experiência em geral, [...] não há experiência de ninguém, a experiência é sempre experiência de alguém, ou dito de outro modo, que a experiência é, para cada um, a sua, que cada um faz ou padece sua própria experiência, e isso de um modo único, singular, particular, próprio (LARROSA, 2011, p. 7).

Retomar as experiências vivenciadas pelos alunos-mestres implica ir além da investigação das relações segmentadas da prática com a teoria, pois busca tratar ambas na relação viva com o sujeito da experiência, considerando que essa análise oferece a oportunidade de uma tomada de consciência intencional e, ao mesmo tempo, subjetiva da constituição da sua própria identidade.

A experiência é um movimento de ida e volta. Um movimento de ida porque a experiência supõe um movimento de exteriorização, de saída de mim mesmo, de saída para fora, um movimento que vai ao encontro com isso que passa, ao encontro do acontecimento. E um movimento de volta porque a experiência supõe que o

\footnotetext{
${ }^{3}$ Síndrome de Gabriela, compreendida como a incapacidade do ser humano, no caso o professor, de acreditar que pode ser diferente do que vem sendo, demonstrando atitudes de negação e resistência às mudanças. Com Dewey, compreendemos que somente a ação reflexiva baseada na experiência pode romper com esse 'status quo' da formação docente, pois "[...] não há crescimento intelectual sem reconstrução, sem que, de algum modo, a forma em que se manifestam de início estes desejos e impulsos seja revista e refeita [...] pensar é, assim, livrar-se da ação imediata, enquanto a reflexão, pela observação e pela memória, efetua o domínio interno do impulso" (DEWEY, 1971, p. 63).
} 
acontecimento afeta a mim, que produz efeitos em mim, no que eu sou, no que eu penso, no que eu sinto, no que eu quero etc. (LARROSA, 2011, p. 7).

Nesse movimento de idas e vindas, de fluxo e de refluxo próprios da experiência, o sujeito, em sua ação reflexiva, passa a 'tomar pé' de suas escolhas e de seus aprendizados, inaugurando outras possibilidades de pensamento e de transformação da sua prática. No campo educativo, isso implica reconhecer que a experiência exige relação e encontro, exige entrega e acolhimento, exige serenidade e inquietude, exige diálogo e escuta, exige renúncia e transformação. A experiência, na potencialidade de seu caráter essencialmente formativo, termina por equacionar, na formação inicial de professores, a transformação da própria identidade docente:

De fato, na experiência, o sujeito faz a experiência de algo, mas, sobretudo, faz a experiência de sua própria transformação. Daí que a experiência me forma e me transforma. Daí a relação constitutiva entre a ideia de experiência e a ideia de formação. Daí que o resultado da experiência seja a formação ou a transformação do sujeito da experiência. (LARROSA, 2011, p. 7).

Pensar a formação inicial de professores de Artes Visuais sob essa ótica implica compreender que o 'devir' formativo da experiência se processa quando o sujeito ativa seus próprios princípios na busca reflexiva de si e do que lhe acontece, um movimento de atravessamento, de mudança que mobiliza sentidos e significados, interrompendo o aligeiramento do tempo e convocando-o a fazer a experiência de sua própria transformação - e isto não se faz em um mar de calmaria, mas na ousada necessidade de suspender o juízo prévio e de colocar-se em situação de risco.

As experiências vivenciadas na formação inicial, em especial no Curso de Licenciatura em Artes Visuais, podem ser compreendidas como uma possibilidade de transformação e conhecimento de si, de reflexão acerca da constituição de sua identidade docente. E nada mais coerente que trazer à tona os saberes da experiência, não como verdades absolutas, mas enquanto modos de compreensão sobre como damos sentido, ou não, àquilo que nos acontece.

Desta forma, refletir a formação inicial de um grupo de licenciandos em arte na experiência e com base nela só se faz possível se compreendemos os processos formativos dos alunos como possibilidade consumatória de suspender ou de interromper a tranquilidade que os habita, as certezas que os consomem e o 'porto seguro' que aprenderam - e construíram - sobre a identidade docente, até mesmo na IES em que estudam. 


\title{
Da experiência na formação inicial na licenciatura: o que relatam os licenciandos?
}

\begin{abstract}
"A formação é como uma viagem aberta, uma viagem que não pode estar antecipada, uma viagem interior, uma viagem na qual alguém se deixa influenciar a si próprio, se deixa seduzir e solicitar por quem vai ao seu encontro, e na qual a questão é esse próprio alguém, a constituição desse próprio alguém, e a prova é desestabilização desse próprio alguém"

LARROSA, 2002.
\end{abstract}

Tomando de empréstimo a perspectiva de Larrosa (2002), podemos considerar a formação como uma espécie de 'viagem aberta', na qual o sujeito - o aluno-mestre - sai ao encontro do outro e ao seu próprio encontro, desassossegando suas verdades e reconfigurando novas maneiras de ser/estar na vida e na própria profissão. Nesta peregrinação em busca de si, leva consigo as experiências mais marcantes: fatos ou situações vivenciadas de caráter formativo, isto é, as experiências simbólicas que o instiga a repensar a identidade docente, sua própria identidade e as relações que tece com a vida e com a profissão.

Para Furlanetto (2011, p. 115), a formação inicial, ao acolher as experiências embreantes dos estudantes, abriga também a potência transformadora que dela advém, desalojando o estudante das fronteiras daquilo que é cômodo e conhecido e instigando-o na busca de outras paragens, já que “[...] esses trânsitos o instigam a descobrir uma nova expressão que requer um novo idioma e uma nova escrita pedagógica, que emerge não da repetição, mas da elaboração da própria experiência e da experiência do outro".

Abandonar convicções que se julgava estáveis e tomar consciência de seu percurso não é fácil, assim como não é se dispor a falar daquilo que o 'toca' em profundidade. Entretanto, e com as pausas necessárias a essa ação/reflexão/ transformação, os alunos-mestres concederam as entrevistas, que por terem um viés semiestruturado, possibilitou-lhes a retomada dos acontecimentos que consideraram formativos em sua formação inicial, buscando aproveitar o momento da entrevista para se apropriar do que tinham vivido:

E quando você fala desse acontecimento eu fico aqui pensando, como as coisas foram mudando na minha vida desde que eu entrei na faculdade, sabe? Por que antes eu penso que tinha mais certeza das coisas, de como seria e hoje eu nem sei se tenho isso mais... Começou com a aquela aula que me desestabilizou... aquela de desenharmos uma flor e que todo mundo fez aquele padrão: pétalas vermelhas, miolos amarelos e folha verde...[risos] Isso desequilibrou toda a minha estrutura, construída durante meu ensino básico... porque foram anos 
desenhando dessa maneira, colocando isso como correto e me adaptando a esse padrão [olhos marejados e voz embargada]... e de repente essa parede se quebra e eu consigo olhar para um horizonte mais amplo, abrir novos caminhos e entender que a arte vai muito mais além daquilo que imaginava... e isso até me dá medo, mas um medo bom, um medo da coragem de descobrir... é, acho que foi ali mesmo que isso tudo começou...e é isso que me anima a continuar a ser professor, essa possibilidade de transformação que aconteceu comigo também acontecer com os meus alunos... ALUNO-MESTRE 'A'.

Essa possibilidade de retomar a experiência vivida amplia a compreensão do feixe de relações entre as experiências formativas e a própria vida, a ponto de permitir que o ALUNO-MESTRE 'A' adentre territórios pouco explorados de sua consciência reflexiva sobre como sua identidade profissional vem se construindo nesse trajeto. Ao recompor na memória a lembrança do vivido, o aluno-mestre procura pensar o que ainda não foi pensado, não como novidade a ser interpretada e anunciada, mas como experiência que produz deslocamentos em seu próprio pensar, sentir e agir.

Esse "medo da coragem de descobrir" manifesto na fala embargada de 'A', implica na desestabilização de suas estruturas cognitivas para gerar um outro aprendizado: o de que na docência em Arte aprender e ser se conectam a todo tempo, de que os conteúdos são atravessados pela subjetividade do sujeito e de que ser professor exige a assunção de uma postura de inconformismo com as questões pré-estabelecidas. Ao mesmo tempo, essa possibilidade de estar numa espécie de 'espaço de fronteira' reflexiva sobre si próprio, corporifica o desejo de ser diferente daquilo que vinha sendo, de transgredir os limites do que se lhe apresenta sobre ser professor.

Aprender a aprender e aprender a ensinar Arte - não necessariamente nesta ordem - compõem-se de práticas sensíveis que demandam “[...] relacionar arte e vida, onde o conhecer, o fazer, o expressar, o comunicar e o interagir instauram práticas inventivas a partir das vivências de cada um" (MEIRA, 2003, p. 122), exigindo disposição, transformação, atos de relacionar e de contextualizar, intervir, mediar, reinventar para realizar. Ações provocadoras que atuam como elementos disparadores de um pensamento reflexivo acerca da própria formação, como 'A' explicitou.

Alimentar esses encontros de formação, encontrar as brechas para refletir sobre si e como as vivências atravessam seu pensar também foi a tônica dos relatos finais de estágio. A proposta era de que os estudantes, partindo de uma escrita mais fluida, colocassem em seus diários de bordo as inquietações que permeiam sua construção identitária. Nesse contexto, o ALUNO-MESTRE 'V' escreveu: 
Fico pensando naquilo que vivi na faculdade mas quero escrever sobre uma experiência estética que aconteceu comigo na semana passado, quando eu estava andando pela rua e me deparei com uma garotinha de uns 3 ou 4 anos. Ela vinha andando pela calçada com uma mulher a seu lado, talvez sua mãe. A garotinha segurava um saco de salgadinho nas mãos, desses tipo 'batata chips'. Vinha contente, vestidinho pink, lacinho no cabelo, a típica bonequinha. Mas o que me chamou a atenção não foi nada disso: ela enfiou a mão no pacote de salgadinho e colocou um punhado na boca, e isso sim fez toda a diferença. Ao colocar o salgadinho na boca, a menina fechou os olhos em uma expressão imensa de contentamento e alegria, sua boca sorriu e o seu passo mudou de um andar compassado para uma dancinha desajeitada. Nesse momento, pensei "essa garota está tendo uma experiência incrível". Talvez por ser a primeira vez que comia aquele salgadinho, talvez por gostar muito de seu sabor... Penso que estudar Artes é estar sempre vivenciando experiências, como a garotinha e seu pacote de salgadinhos. Sai o pacotinho e no lugar temos um universo cheio de sensações prontas a nos proporcionar experiências... como a menina abrindo seu pacotinho, abrimos nossos olhos ao mundo e a arte nos faz sorrir e dançar de contentamento! Agora andar pelas ruas não é apenas sair de um ponto a outro. É perceber que a nova coleção de calçados na vitrine lembra a Frida Kahlo, que a mancha na parede remete a Pollock, as novas arquiteturas residenciais são minimalistas. Perceber igrejas góticas e neoclássicas. As cores da tendência da moda são à la Mondrian e andam pelas ruas os mestiços de Portinari, madames de Picasso e homens amarelos de Malfatti. As músicas já não são de Bach nem de Beethoven e que o caos do trânsito faz lembrar Hermeto. Os outdoors estão carregados de belezas gregas e ideologias da Pop Art. Viver a arte em sua plenitude é estar a todo momento abrindo o meu pacotinho de experiências, abrindo os olhos, a mente e o coração. Estar disposto a vivenciar uma experiência estética é perceber que o simples gesto de uma garotinha de apenas 3 ou 4 anos pode nos ensinar muito sobre a vida e sobre o que eu penso dela. ALUNO-MESTRE 'V' (Relatório Final de Estágio, 2014).

Desnudar as experiências carregadas dos segredos que o compõem, revelando a forma como se posiciona diante da vida e de como confere sentido ao que lhe acontece, possibilita ao estudante acessar dimensões da sua identidade docente muito pouco analisadas profissionalmente; ao se depararem com essa forma de acesso, os alunosmestres revisitam seu discurso pedagógico e descobrem sobre quais concepções se assentam, angariando bases para uma possível mudança.

' $\mathrm{V}$ ', ao descrever a experiência vivenciada e ao refletir sobre ela, consuma a concepção de experiência de Larrosa (2002), como essa possibilidade de parar e dar tempo para que as coisas aconteçam, de não ficar procurando por "a" experiência, mas estar aberto aos acontecimentos que lhe atravessam. A reflexão sobre o ocorrido alimenta a autoconfiança, ao mesmo tempo que traz questões, dúvidas e incertezas que 
precisam ser colocadas em jogo, precisam ser refletidas para uma melhor ampliação da conscientização, da autonomia e da responsabilidade na e com sua formação docente.

$\mathrm{Na}$ especificidade do ensino de Arte, e na complexidade da formação inicial de professores em Arte, essa articulação necessita oportunizar a interação com o seu campo de conhecimento: a Arte, promovendo o estudo e a análise das diversas representações simbólicas articuladas aos seus contextos culturais, históricos, sociais e antropológicos, da Educação enquanto saber sistematizado, das relações críticas da docência, em uma estreita ligação com uma poética pessoal do licenciando. E se isso não vem acontecendo - ou vem acontecendo superficialmente - é porque a formação inicial ainda não assumiu toda sua potencialidade.

Quando questionado sobre uma experiência que considere formativa, o ALUNO-MESTRE 'B' respondeu:

\begin{abstract}
Ah professora! Por que me pergunta assim? São tantas as coisas que eu vivi nesse tempo que eu nem consigo descrever! Porque quando eu comecei aqui na faculdade eu pensava de um jeito e agora, com tudo que eu conheci e que nem sabia que existia, tudo mudou. Tô aqui relembrando e tem tanta coisa... é acho que essa é uma coisa que me fez pensar sim... e tem a ver como um provocação que foi feita lá na disciplina, que a gente tinha que criar uma aula para apresentar na classe em que o centro não fosse o professor, mas as relações, o conteúdo, o aluno ser o protagonista. E nisso eu me vi enroscada, me vi pensando, como vou ser professora e tenho que dar uma aula que o foco não esteja centrado em mim? Como assim? A aula era minha! A lousa era parte do meu ser professora! Sempre foi assim e abrir mão disso, naquele momento, doeu muito... ALUNO-MESTRE 'B'.
\end{abstract}

Esse deslocamento das certezas vivenciado pela experiência provocada em sala de aula leva o aluno-mestre a questionar sobre seu papel na docência. Sentir-se detentor da 'lousa', como máxima representação da autoridade de um saber docente não é uma postura que se espera de um estudante nos momentos finais de sua formação inicial. Entretanto, ao dar visibilidade ao que lhe aconteceu, o estudante considera o fato como uma experiência formativa, uma vez que lhe permitiu refletir sobre essas questões, narrativas que interligam e dão sentido às noções sobre as quais somos ensinados e sobre as quais se assentam nossas bases estruturais do pensamento acerca da docência.

O aluno-mestre, ao buscar interpretar aquilo que é vivenciado, questiona sua prática e reorienta suas ações no mesmo momento que as vivencia, como ponderou 'B':

Essa ideia de voltar a olhar para mim, de revisitar a minha história e redescobrir o porquê das minhas escolhas, o porquê de ser professor, é também ter outras possibilidades de atuação no presente, porque ao 
mesmo tempo que eu faço essas conexões sobre o meu posicionamento como professora de arte, eu também vejo esse lugar de aluna e como eu vou me construindo nessa dupla função. Quando leio um texto, escuto uma música ou elaboro uma produção visual, essas questões vão interagindo em como eu posso ser professora, uma professora melhor! Essa ideia de ser boa professora tem a ver com tudo o que eu já vivi, aqui na faculdade e na escola, com toda essa experiência que vamos acumulando e que vai me revirando do avesso... ALUNO-MESTRE 'B' (Relatório Final de Estágio, 2014).

Pensar sobre as próprias escolhas é trabalhar com dispositivos do reconhecimento de outro campo de forças que atua diretamente na constituição identitária: seja na escolha dos modelos a seguir, seja na escolha da permanência ou na assunção dos riscos de se fazer na diferença pedagógica. Ao desenvolver essa compreensão, provocada pela experiência, o aluno-mestre tem a possibilidade de interferir no seu caminhar, ele não é simplesmente consequência das situações vividas, mas autor de sua identidade. Virar-se do avesso se torna a metáfora de um movimento disruptivo de construção de si. Trata-se, antes, de uma ressignificação da identidade docente deste aluno, como também explicita o aluno-mestre ' $\mathrm{C}$ ':

Quanta coisa mudou e continua mudando. Antigamente via Arte somente como um fazer artístico, pois era a experiência que tive no decorrer da minha formação na escola. Claro que quebrei a cara né [risos]. Hoje costumo dizer que me sinto como se estivesse tendo aulas de Arte pela primeira vez na vida. Me lembro que logo quando entrei no curso, queria porque queria desenhar realisticamente, até que um dia a professora de desenho me perguntou o porquê disso? O que me faria melhor como pessoa desenhando realisticamente? E é claro que no momento não soube responder... mas hoje vejo que minha visão sobre o "belo" era limitado a isso. Quantos paradigmas quebrados! A sensação é de ser desconstruído e reconstruído dia após dia. E essa é uma experiência incrível! Hoje percebo a importância do ensino de Arte nas escolas para formação integral do ser humano, e me sinto lisonjeado desde já em fazer parte desse "batalhão". ALUNO-MESTRE 'C'.

Essa sensação de construção/desconstrução que aponta o estudante, baseado nas experiências vivenciadas em sua formação inicial possibilita um exame crítico de suas escolhas, de suas intenções e de suas concepções, estabelecendo a possibilidade de exercitar um pensamento acerca da profissão escolhida, comportando uma articulação consciente entre ideias, ações, afetos e a experiência formadora. Trata-se, também, do reconhecimento, da validação e da legitimação de sua subjetividade e de sua identidade profissional. 
As narrativas sobre a experiência formativa na constituição da identidade docente, construídas com base na reflexão sobre as vivências de cada aluno-mestre, ainda que de forma singular e individualizada, podem reverberar no grupo maior de estudantes, à medida que estes se identifiquem no conjunto de experiências. Ao colocarmos em cena as boas práticas reflexivas dos colegas, propiciamos tanto sua tematização, com a análise das condições de seu desenvolvimento e os efeitos advindos dela, como permitimos que os alunos-mestres compartilhem suas singularidades, transformando seu fazer docente e discente. Embora a reflexão seja individual, ela pode se transformar em experiência compartilhada e auxiliar ao grupo na articulação entre trabalho e identidade profissional.

\section{Considerações finais}

As manifestações dos alunos-mestres, construídas com base na reflexão sobre as experiências vivenciadas, ainda que de forma singular e particular, encontram ecos no grupo dos estudantes da Licenciatura, na medida em que eles se identificam com elas. Esse partilhar é extremamente fecundo na formação inicial, pois permite aos licenciandos perceberem-se como profissionais em constante formação; que a transformação de suas práticas docentes depende da modificação da forma pela qual construíram sua identidade pessoal em relação ao seu trabalho profissional (LARROSA, 2000). O outro me ajuda a aprender, assim como esse outro também aprende nessa relação.

Nessas relações reflexivas, eles encontram os mecanismos conscientes para modificar sua atuação profissional, reorganizando a reverberação que essas experiências individuais assumem em seu percurso formativo e no âmbito escolar em que atuam, compreendendo que

Em sua performance solitária em sala de aula, cada educador [licenciando] pode reconhecer em sua voz e gestos, ecos das condutas de tantos outros mestres cujo comportamento desejou imitar; ou silêncios de tantos outros cuja atuação procurou recalcar. (NÓBREGA; PRADO, 2013, p. 5).

Acolher a experiência - sua e do outro - como disparadora de um pensar, constitui-se, em primeira mão, como uma dimensão formativa da docência, pois é refletindo sobre o vivido e ressignificando-o que os estudantes vão se aproximando da 
identidade profissional de professor, investigando os atalhos únicos e diferenciados que os caracterizam em sua ação educativa.

Acreditamos que a presente investigação tenha lançado pontos de luz na compreensão das experiências vivenciadas na composição da identidade docente do licenciando em Artes Visuais, em que a vida não está posta nos livros ou nos manuais, mas pulsa no diálogo entre teoria e prática, mantendo-se no horizonte de que ser docente implica a assunção de uma postura profissional complexa e não mera tarefa de pauta burocrática. Desta forma, o estudo não teve como pretensão a produção de determinada teoria ou programa pedagógico, tampouco a sistematização de procedimentos que podem ser copiados e reproduzidos, nem mesmo referendar modos de ser professor, mas sim, e tão somente, compor um marco reflexivo acerca da formação inicial de professores de Artes Visuais que possa ser partilhado, debatido e transformado.

\section{Referências}

BARDIN, J. L’ére logique. Paris: Robert Laffont, 1977.

BARREIRO, I. M. F.; GEBRAN, R. A. Prática de ensino e estágio supervisionado na formação de professores. São Paulo: Avercamp, 2006.

DEWEY, J. Arte como experiência. São Paulo: Martins Fontes, 2011.

DEWEY, J. Como pensamos. São Paulo: Nacional, 1959a.

DEWEY, J. Democracia e educação. São Paulo: Nacional, 1959b.

DEWEY, J. Experiência e educação. São Paulo: Nacional, 1971.

ECO, U. Obra aberta: forma e indeterminação nas poéticas contemporâneas. São Paulo: Perspectiva, 2008.

FREIRE, P. Pedagogia da autonomia: saberes necessários à prática educativa. São Paulo: Paz e Terra, 1996.

FREIRE, P. Professora sim, tia não: cartas a quem ousa ensinar. São Paulo: Olho d'Água, 1998.

FURLANETTO, E. C. F. A formação como possibilidade de reconhecimento e transformação de matrizes pedagógicas. In: FONTOURA, H. A.; SILVA, M. Formação de professores, culturas: desafios à pós-graduação em educação em suas múltiplas dimensões. Rio de Janeiro: ANPED Nacional, 2011. p. 107-118. 
GARCIA, C. M. A identidade docente: constantes e desafios. Revista Formação Docente, Belo Horizonte, v. 1, n. 1, p. 109-131, ago./dez. 2009. Disponível em: <http://formacaodocente.autenticaeditora.com.br>. Acesso em: 01 jul. 2014.

GARCIA, C. M. Formação de professores: para uma mudança educativa. Porto: Porto Editora, 1999.

GARCIA, C. M. Pesquisa sobre formação de professores: o conhecimento sobre aprender a ensinar. In Revista Brasileira de Educação, n. 9, São Paulo, ANPED-Bartira Gráfica e Editora, set/out/nov. 1998, p. 51-75.

HERNANDEZ, F. A construção da subjetividade docente como base para uma proposta de formação inicial de professores de artes visuais. In: OLIVEIRA, M. O.; HERNANDEZ, F. A formação do professor e o ensino de artes visuais. Santa Maria, RS: Ed. UFSM, 2005. p. 21-42.

LARROSA, J. Experiência e alteridade em educação. Reflexão \& Ação, Santa Cruz do Sul, RS, v. 19, n. 2, p. 4-27, 2011.

LARROSA, J. Notas sobre a experiência e o saber da experiência. Revista Brasileira de Educação [online], São Paulo, n. 19 p. 20-28, 2002. Disponível em: <http://http://www.scielo.br/scielo.php?script=sci_arttext\&pid=S1413-

24782002000100003 >. Acesso em: 02 dez. 2012 Na publicação não consta o volume

LARROSA, J. Tecnologias do eu e Educação. In: SILVA, T. T. (Org.). O sujeito da educação: estudos foucaultianos. Petrópolis: Vozes, 2000. p. 35-86.

MACHADO, N. J. Educação: projetos e valores. São Paulo: Escrituras, 2000.

MATTAR, S. A deflagração de projetos criadores na arte e na educação: uma perspectiva dialógica, inventiva, experimental e investigativa na formação de professores de arte no âmbito da graduação e da pós-graduação. In: GERALDO, S. C., COSTA, L. C (Orgs.). In: Encontro da associação nacional de pesquisadores em artes plásticas, 2011, Rio de Janeiro. Anais... Rio de Janeiro: ANPAP, 2011.

MEIRA, M. Filosofia da criação: reflexões sobre o sentido do sensível. Porto Alegre: Mediação, 2003.

MONTALVÃO, E. C.; MIZUKAMI, M. G. N. Conhecimentos de futuras professoras das séries iniciais do ensino fundamental: analisando situações concretas de ensino e aprendizagem. In: MIZUKAMI, M. G. N.; REALI, A. M. M. R. Formação de professores, práticas pedagógicas e escola. São Carlos: EdUFSCar, 2010.

p. $101-126$.

NÓBREGA, M. J.; PRADO, R. Apresentação. In: IAVELBERG, R. Desenho na educação infantil. São Paulo: Melhoramentos, 2013. p. 5-07.

NÓVOA, A. (Org.). Os professores e sua formação. Lisboa: Don Quixote, 1995.

PEREIRA, M. V. Estética da professoralidade: um estudo crítico sobre a formação do professor. Santa Maria: Ed. da UFSM, 2013. 
PIMENTA, S. G. (Org.). Saberes pedagógicos e atividade docente. São Paulo: Cortez, 1999.

TARDIF, M. Saberes docentes e formação profissional. Petrópolis: Vozes, 2012.

ZABALZA, M. A. Diários de aula: Contributo para o estudo dos dilemas práticos dos professores. Porto: Porto Editora, 1994.

ZEICHNER, K. M. A formação reflexiva de professores: Idéias e práticas. Lisboa: Educa, 1993.

ZEICHNER, K. M.; LISTON, D. Reflective teaching: an introduction. Nova Jersey: Lawrence Erlbaum Ass Publis., 1996.

\section{Como referenciar este artigo}

GUIMARÃES, Ana Luiza Bernardo. Como obra aberta: do constituir-se professor na formação inicial. Revista on line de Política e Gestão Educacional, Araraquara, v.20, n.2, p. 478-500, 2016. Disponível em: <http://dx.doi.org/10.22633/rpge.v20.n3.9756>. ISSN: 1519-9029.

Submetido em: junho/2016

Aprovado em: julho/2016 